\title{
The use of bacterial luciferase for monitoring the environmental regulation of expression of genes encoding virulence factors in Listeria monocytogenes
}

\author{
Simon F. ParK, ${ }^{1 *}$ Gordon S. A. B. Stewart ${ }^{2}$ and Rohan G. Kroll ${ }^{1}$ \\ 'Department of Microbiology, AFRC Institute of Food Research, Reading Laboratory, Earley Gate, Whiteknights Road, \\ Reading RG6 $2 E F, U K$ \\ ${ }^{2}$ University of Nottingham, Department of Applied Biochemistry and Food Science, Sutton Bonington, \\ Leicestershire LEI2 5RD, UK
}

(Received 14 April 1992; revised 7 July 1992; accepted 26 August 1992)

\begin{abstract}
A promoter probe vector, which utilized the $\operatorname{lu} A B$ genes from Vibrio fischeri as reporters of gene expression, was constructed for use in Listeria monocytogenes. Using this system gene expression can be monitored nondestructively and in real-time, simply by measuring cellular bioluminescence. Derivatives of the promoter probe were constructed that contained the cloned promoters from the $h l y A$ and plcA genes of $L$. monocytogenes. The activity of these promoters was dependent on the transcriptional activator PrfA. Accordingly, in a strain containing an intact copy of the $\operatorname{prf} A$ gene, expression from both the $h l y A$ and $p l c A$ promoters was 25-45-fold higher than in prf $A$ mutants. Heat shock was identified as an environmental signal which induced expression of $h l y A$ and plcA. Conversely, oxidative stress had no effect upon the expression of the virulence factors. In addition, the composition of the growth media was found to have a dramatic effect upon the expression of $h l y A$ and $p l c A$, suggesting the presence of an unidentified signal which may regulate induction of expression of virulence genes in L. monocytogenes.
\end{abstract}

\section{Introduction}

Listeria monocytogenes is an ubiquitous Gram-positive pathogen responsible for a variety of infections in a wide range of animals and is now recognized as a foodborne pathogen of significance to humans (Farber \& Peterkin, 1991). A key factor in the pathogenicity of L. monocytogenes is its ability to survive and multiply within macrophages (Mackaness, 1962) and at least two virulence factors have been implicated in this phenomenon. The most widely studied is the listeriolysin $\mathrm{O}$ (Cossart \& Mengaud, 1989), which disrupts the phagosomal membrane and is essential for virulence (Gaillard et al., 1986; Michel et al., 1990). Listeriolysin is encoded by the hlyA gene (Mengaud et al., 1988) and regions located $5^{\prime}$ and $3^{\prime}$ of this gene also encode virulence factors (Mengaud et al., 1989). Cells containing mutations in the plc $A$ gene, which is located upstream of $h l y A$ and encodes a phospholipase C (Leimeister-Wächter et al., 1991; Mengaud et al., 1991a), have attenuated virulence (Camilli et al., 1991; Mengaud et al., 1991a). Additionally, a metalloprotease encoded by the $\mathrm{mpl}$ gene

\footnotetext{
- Author for correspondence. Tel. (0734) 357000; fax (0734) 267915.
}

(Domann et al., 1991; Mengaud et al., 1991b) and a lecithinase encoded by the $p l c B$ gene (Vazquez-Boland $e t$ al., 1992) may play roles in the infection process and in intercellular spread.

Co-ordinated regulation of virulence factors enables the pathogen to respond to the diverse range of environments encountered during the infection process. The hly $A$ and plcA genes are located back-to-back on the L. monocytogenes chromosome and are transcribed from divergent overlapping promoters (Mengaud et al., 1989). Expression of both these genes is co-ordinately regulated by a pleiotropic activator for virulence gene expression which is encoded by the $\operatorname{prf} A$ gene (Leimeister-Wächter et al., 1990; Mengaud et al., 1991c). Strains of L. monocytogenes which harbour deletions in this gene do not transcribe either the listeriolysin or phospholipase $\mathrm{C}$ genes and, accordingly, have reduced virulence (Mengaud et al., 1991c; Chakraborty et al., 1992). Additionally, PrfA is known to co-ordinately regulate the expression of other genes in the virulence chromosomal region (Vazquez-Boland et al., 1992; Chakraborty et al., 1992), the products of which include metalloprotease $(m p l)$, lecithinase $(p l c B)$ and an actin nucleation factor ctA). 
Table 1. Bacterial strains and plasmids

\begin{tabular}{llr}
\hline \hline Strain/plasmid & \multicolumn{1}{c}{ Characteristics } & Origin* \\
\hline $\begin{array}{l}\text { Strains } \\
\text { L. monocytogenes }\end{array}$ & & \\
7973 & Haemolytic & 1 \\
10357 & prf $A \Delta$, non-haemolytic & 1 \\
HM1 & prf $A \Delta$, non-haemolytic & 2 \\
Plasmid & & \\
pCK1 & CmR Km R $^{\mathrm{R}}$ broad host range & 3 \\
pSB185 & pBR322 derivative with promoterless luxAB & 4 \\
pSB283 & pCK1 derivative with no BamHI + EcoRI sites & 2 \\
pSB285 & pCK1 derivative with promoterless luxAB & 2 \\
pSB292 & Promoter probe vector with luxAB markers & 2 \\
pSP13 & pSB292 with cloned constitutive promoter & 2 \\
pSP38 & plcA-luxAB fusion vector & 2 \\
pSP39 & hlyA-luxAB fusion vector & 2 \\
\hline \hline
\end{tabular}

* 1, National Collection of Type Cultures, Colindale, London, UK; 2, this study; 3, Gasson \& Anderson (1985); 4, Ahmad \& Stewart (1988).

The use of gene fusions now constitutes a wellestablished method for the study of gene expression and characterization of transcriptional control signals (Silhavy \& Beckwith, 1985). Although reporter gene systems have already been constructed for use in Bacillus spp. and Lactobacillus spp., and these may well operate in $L$. monocytogenes, the only reporter gene systems which have so far been used in this bacterium are a $\operatorname{Tn} 917-$ based transposon, which has potential use as a lacZbased operon fusion system (Camilli et al., 1990), and a plasmid vector which can be used to generate gene fusions to lacZ (Leimeister-Wächter et al., 1992).

This report describes the construction of a bacterialluciferase-based promoter probe plasmid for use in $L$. monocytogenes. The use of the lux $A B$ genes as markers of gene expression conveys the readily selectable phenotype of bioluminescence (Meighen, 1991). Assays for luciferase are simple and do not compromise cellular viability so that the induction of gene expression from a given promoter can be monitored in real-time, in situ and in complex environments. The utility of the vector system was demonstrated by constructing lux $A B$ fusions to the $h l y A$ and $p l c A$ promoters and this has allowed the identification of environmental signals which regulate the expression of virulence genes in $L$. monocytogenes.

\section{Methods}

Bacterial strains, transformations and growth conditions. The bacterial strains used are described in Table 1: For routine growth, L. monocytogenes was grown in Tryptone Soy Broth (TSB; Oxoid) at $37^{\circ} \mathrm{C}$. Strains were transformed with plasmid DNA using electroporation as described by Park \& Stewart (1990). Selection for plasmids in $L$. monocytogenes was made by incorporating chloramphenicol into growth media at $5 \mu \mathrm{g} \mathrm{ml}^{-1}$. When the effect of media composition on virulence gene expression was studied, $L$. monocytogenes was grown overnight in Brain Heart Infusion Broth (BHI; Oxoid) or TSB at $37^{\circ} \mathrm{C}$.
The cells were recovered by centrifugation, washed and then resuspended in an equal volume of the new media. This inoculum was diluted 1:50 into fresh media and incubation continued at $37^{\circ} \mathrm{C}$ with aeration.

Plasmids and sequencing. The plasmids used and constructed in this study are listed in Table 1. Plasmid constructions were performed in Escherichia coli JM101 using standard techniques (Maniatis et al., 1982). The identity of the $464 \mathrm{bp}$ PCR-generated DNA fragment from the intergenic region between $h l y A$ and plcA was confirmed using a plasmid based dideoxy sequencing system (Bartlett et al., 1986).

$P C R$ reactions. Two $37-$ mer primers were designed to enable the cloning of the hlyA-plcA intergenic region. The primer with homology to the $5^{\prime}$ terminus of $h l y A$ had the sequence: $5^{\prime}$ CGCATGGATCCGAATTCGTCTCCGTTATAGCTCATCG3'. The non-homologous region, which introduced sites for $B a m H I$ and $S m a I$ into the end of the $P C R$ product, is underlined and the translational start codon for $h l y A$ is shown in bold. The second primer, with homology to the $5^{\prime}$ end of plcA, had the sequence: 5 'GCGATCCCGGGGGATCCCATGGTTTCACTCTCCTTC3'. The $5^{\prime}$ non-homologous region in this primer introduced BamHI and SmaI sites and formed an Ncol site with the existing DNA sequence. Primers were included in PCR reactions at 20 pmol. Target DNA was prepared from $L$. monocytogenes by the method of Pitcher et al. (1989) and used at a concentration of $1 \mu \mathrm{g} \mathrm{ml}^{-1}$. A commercial Taq DNA polymerase and buffer system (Amersham) was used to amplify the target in the presence of deoxynucleotides $(50 \mu \mathrm{M})$. A total of 26 cycles was used to amplify the target region and each cycle included a $30 \mathrm{~s}$ denaturation step at $94^{\circ} \mathrm{C}$ and a $30 \mathrm{~s}$ annealing step at $55^{\circ} \mathrm{C}$, followed by a 2 min extension step at $72^{\circ} \mathrm{C}$. The $464 \mathrm{bp}$ fragment generated by this procedure was resolved by agarose electrophoresis and recovered from the gel by Prepagene (Bio-Rad). Following digestion with BamHI, the fragment was cloned directly into the corresponding sites of the promoter probe vector, PSB292. The integrity of the $p r f A$ gene in the various strains of L. monocytogenes was determined by PCR using chromosomal DNA from the respective strains as template and the primers: 5'ATGAACGCTCAAGCAGAAGA3' and 5'TCTGTTGCAGCTCTTCTTGG3'. Cycling parameters were the same as those described above.

Luciferase assays and stress experiments. To measure steady state gene expression from $h l y A$ and $p l c A$ fusions to $\operatorname{lux} A B$, various strains of $L$. monocytogenes were grown overnight in TSB diluted 1:50 into fresh media and grown with agitation to an $\mathrm{OD}_{600}$ of 0.4 . Simultaneous 
luciferase assays and optical density measurements were then taken. For heat shock and oxidative stress experiments, cells were grown similarly, to an optical density of $0 \cdot 2$, when either $\mathrm{H}_{2} \mathrm{O}_{2}$ was added or samples were transferred to a $49^{\circ} \mathrm{C}$ waterbath for $30 \mathrm{~min}$ before being returned to $37^{\circ} \mathrm{C}$. Regular measurements of optical density and luciferase were then made. Luciferase activity was assessed in vivo by removing $1 \mathrm{ml}$ samples and adding $20 \mu 1 \mathrm{l} \%(\mathrm{v} / \mathrm{v})$ decanal solution in ethanol. Bioluminescence was assessed immediately in an LKB luminometer. Activity is given by the peak of the light intensity measured.

\section{Results}

\section{Construction of a broad host range promoter probe} plasmid

Plasmid pCK1 (Gasson \& Anderson, 1985) is a broad host range Gram-positive vector which replicates in both Escherichia coli and L. monocytogenes (Park \& Stewart, 1990). This vector contains two unique EcoRI and BamHI sites, which were not desirable in the completed promoter probe vector. Consequently, these two sites were removed by digesting the plasmid with the respective enzymes, removing the intervening fragment and filling the cohesive ends. The plasmid formed by ligation of these ends was designated pSB283 (Fig. 1). A promoterless copy of the Vibrio fischeri luxAB genes was then introduced into this backbone. The plasmid pSB185 (Ahmad \& Stewart, 1988) contains a promoterless copy of the $\operatorname{lux} A B$ genes but retains the native ShineDalgarno sequence (Fig. 1). This is preceded upstream by stop codons in all three reading frames and a unique EcoRI site. In addition, the TL transcriptional terminator from $\lambda$ is located downstream of the lux genes. The terminated lux genes were removed from this plasmid as a $2500 \mathrm{bp} \mathrm{HpaI}$ fragment, generated by partial digestion, and cloned into the unique PvuII site of pSB283. Plasmids containing both orientations of the lux cassette were recovered but only one, containing the orientation shown by pSB285, was analysed further. A synthetic oligonucleotide was cloned into the EcoRI site of this vector to introduce unique cloning sites for promoter cloning. The completed promoter probe plasmid was designated pSB292 (Fig. 1). In the absence of cloned promoters no luciferase activity was detected when this vector was introduced into $L$. monocytogenes (results not shown).

\section{Cloning of the intergenic region between hly $A$ and plcA which contains divergent promoters}

The hlyA and plcA genes, which encode two major virulence factors (Mengaud et al., 1988; LeimeisterWächter et al., 1991), are located on the L. monocytogenes

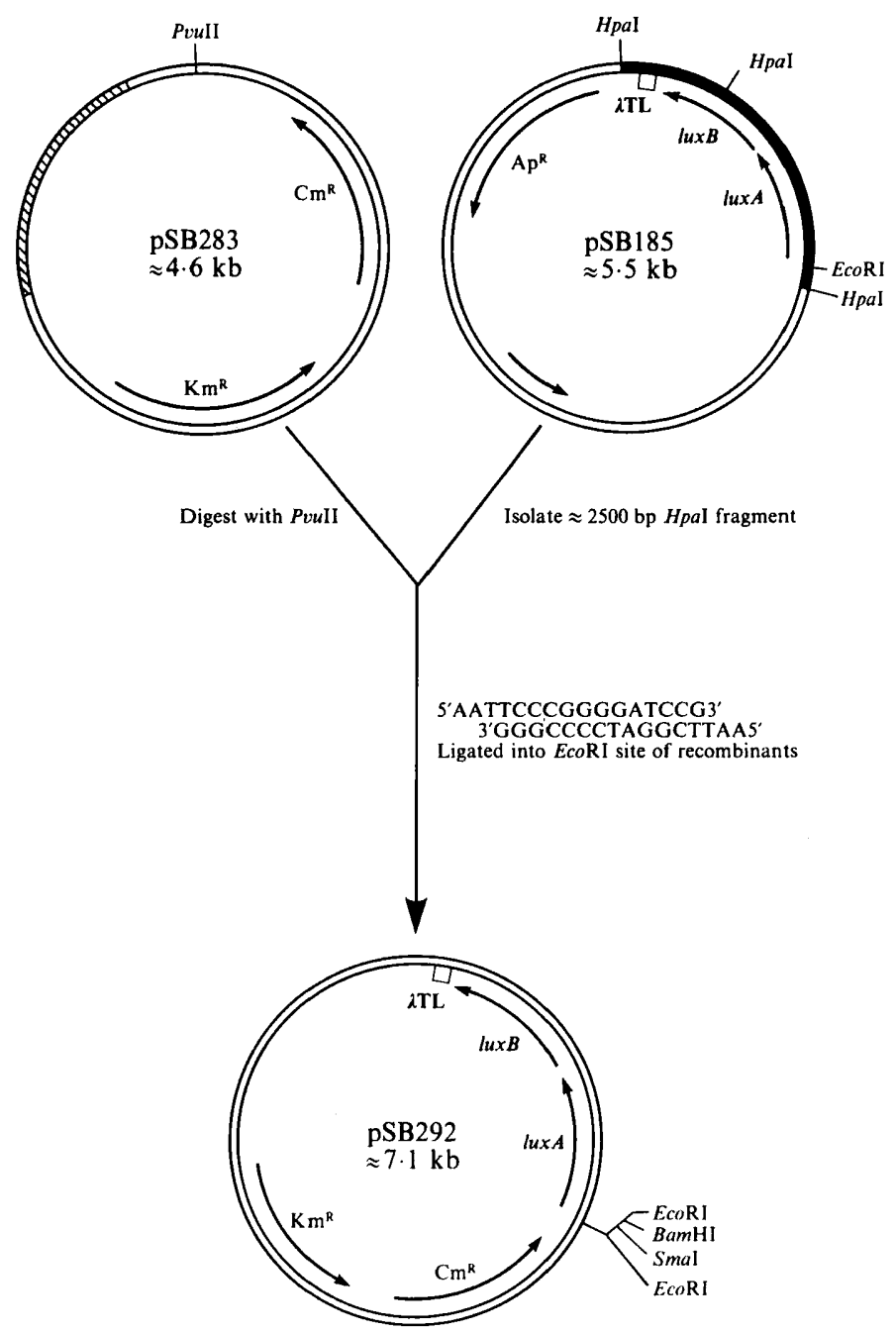

Fig. 1. Construction of the luxAB promoter probe vector, pSB292. The hatched area contains the $\mathrm{pCK} 1$ origin of replication and the filled area represents the luxAB Hpal fragment cloned into pSB283; TL shows the bacteriophage $\lambda$ TL transcriptional terminator. Genes encoding ampicillin $(\mathrm{Ap})$, chloramphenicol $(\mathrm{Cm})$ and kanamycin $(\mathrm{Km})$ resistance are shown.

chromosome in a back-to-back arrangement and are transcribed by divergent promoters (Mengaud et al., 1989). The hlyA gene is transcribed from two promoters separated by $10 \mathrm{bp}$, whilst plcA is transcribed in the opposite direction from a single promoter. A $14 \mathrm{bp}$ palindromic region is present in the -35 region of these promoters and those of other genes encoding virulence factors, and may be responsible for binding the positive regulator of virulence gene expression. To enable the study of environmental signals, which may regulate virulence gene expression and thus prove the utility of the promoter probe vector, this $464 \mathrm{bp}$ intergenic region was cloned by PCR. Primers for PCR were designed to hybridize to the $5^{\prime}$ end of $p l c A$ and the $5^{\prime}$ end of $h l y A$. The $464 \mathrm{bp}$ PCR product defined by these primers was 


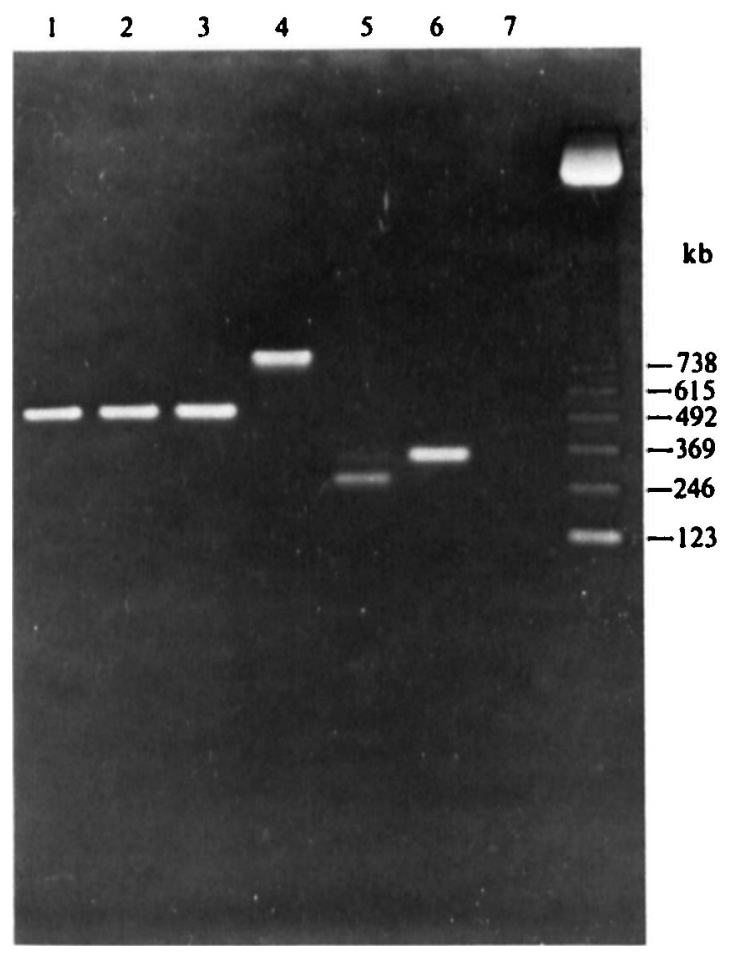

Fig. 2. Detection of deletions in the $\operatorname{prf} A$ gene of various strains of L. monocytogenes using PCR. Lanes: 1, 2, 3, PCR products obtained by using universal primers to rRNA and DNA from NCTC 7973, NCTC 10357 and $\mathrm{HMl}$ as target; 4, 5, 6, PCR products obtained by using primers to the $\operatorname{prf} A$ gene and DNA from NCTC 7973, NCTC 10357 and $\mathrm{HMI}$ as target; 7, PCR control performed in the absence of template DNA.

digested with $\mathrm{BamHI}$ and cloned into the promoter probe vector pSB292. The identity of the cloned fragment was confirmed by DNA sequencing and was shown to have $96 \%$ identity with the published sequence for the plcAhlyA intergenic region (Mengaud et al., 1989). The changes in the nucleotide sequence were confined to regions which were unlikely to be involved in the regulation of gene expression and, therefore, may have represented strain-specific sequence differences that have been observed for the virulence genes (Rasmussen et al., 1991). Depending on the orientation of this fragment, expression of the lux $A B$ marker genes could have occurred from either the plcA promoter or the tandemly arranged and divergent $h l y A$ promoters. The two orientations of the promoter bearing DNA fragment were identified by digesting recombinant plasmids with NcoI. In plasmid pSP38, the orientation of the cloned DNA was such that transcription of the luxAB genes occurred from the plcA promoter and, conversely, in pSP39 expression of the markers was directed by the dual promoters of the hly $A$ gene.

Regulation of hlyA and plcA expression by the product of the prfA gene

The product of the $\operatorname{prfA}$ gene is a pleiotropic regulator required for virulence gene expression. Strains of L. monocytogenes which harbour deletions in this gene do not express plcA, hlyA or other virulence factors (Mengaud et al., 1991 c; Chakraborty et al., 1992) and, consequently, have decreased virulence. To confirm that this regulation occurred at the transcriptional level, and to test the utility of the promoter probe vector, we monitored the activity of the promoters of $h l y A$ and $p l c A$ by assessing luciferase expression from the corresponding promoter probe constructs, both in the absence and presence of the $\operatorname{prf} A$ gene product. The plasmids pSP38 and pSP39 were introduced into the several strains of L. monocytogenes by electroporation (Park \& Stewart, 1990). L. monocytogenes NCTC 7973 is virulent and haemolytic so is likely to contain the $\operatorname{prfA}$ gene. Conversely, strain NCTC 10357 (NCTC Type Strain) is avirulent, does not express phospholipase $\mathrm{C}$ or haemolysin, and has been shown previously to contain a deleted

Table 2. Regulation of gene expression from hlyA-luxAB and plcA-luxAB fusions by the prfa gene product

The activities correspond to those obtained in a typical experiment. Similar results were reproducibly obtained in several experiments.

\begin{tabular}{|c|c|c|c|c|}
\hline \multirow[b]{2}{*}{ Plasmid* } & \multirow[b]{2}{*}{ Strain $†$} & \multicolumn{3}{|c|}{ Luciferase activity [light units $\left(\mathrm{OD}_{600}\right)^{-1}$ ] } \\
\hline & & $\begin{array}{l}\text { NCTC } 7973 \\
\quad\left(p r f A^{+}\right)\end{array}$ & $\begin{array}{l}\text { NCTC } 10357 \\
\quad(\operatorname{prf} A \Delta)\end{array}$ & $\begin{array}{c}\mathrm{HMl} \\
(p r f A \Delta)\end{array}$ \\
\hline pSP39 $(h l y A)$ & & 270 & 12 & 6 \\
\hline pSP38 (plcA) & & 25 & 2 & 1 \\
\hline pSP13 (constitutive) & & 806 & 616 & 651 \\
\hline
\end{tabular}

* The promoter activity which is fused to lux $A B$ in each plasmid is indicated in parentheses.

$\dagger$ The relevant genotype of each strains is indicated in parentheses. 
copy of the prfA gene (Leimeister-Wächter et al., 1990). A second $p r f A$-deleted strain, HM1 (which arose in the laboratory as a spontaneous non-haemolytic mutant of L. monocytogenes (7973) was also used. To confirm the genotype of these strains with respect to $\operatorname{prf} A$, two PCR primers were designed to anneal to the $5^{\prime}$ and $3^{\prime}$ end of the $\operatorname{prf} A$ gene sequence (Mengaud et al., 1991c). PCR was then performed using these primers and chromosomal DNA from the various strains of $L$. monocytogenes as the target. The presence of an intact copy of $\operatorname{prf} A$ was confirmed in NCTC 7973 by the generation of an $830 \mathrm{bp}$ DNA fragment (Fig. 2), which was as predicted for an intact $\operatorname{prf} A$ sequence (Mengaud et al., 1991c). For strains NCTC 10357 and HM1, PCR generated DNA fragments of $270 \mathrm{bp}$ and $340 \mathrm{bp}$ respectively. This confirmed a $560 \mathrm{bp}$ deletion in the prfA gene of NCTC 10357 (Mengaud et al., 1991 c) and identified a $490 \mathrm{bp}$ deletion in the same gene of the non-haemolytic strain HM1. Interestingly, an identically sized deletion was identified in strain ATCC 43250 (Mengaud et al., 1991c). When universal primers to bacterial $16 \mathrm{~S}$ ribosomal RNA genes (Lane et al., 1985) were used as positive controls in PCR reactions all target strains produced the expected $500 \mathrm{bp}$ fragment (Fig. 2).

The activities of the $h l y A$ and $p l c A$ promoters were assessed by measuring the bioluminescence from strains containing the $\operatorname{lu} x A B$ fusion plasmids. As expected, in strains NCTC 10357 and HM1, the absence of an intact copy of the prfA gene led to low levels of $\operatorname{lu} x A B$ expression from both promoters (Table 2). However, in NCTC 7973, which contains an intact copy of $\operatorname{prf} A$, expression of luxAB was 22-45-fold higher for the hly $A$ promoters and 12-25-fold higher for the promoter from plc $A$. Interestingly, the promoters from the $h l y A$ gene also led to higher expression of luxAB than that from plc $A$, as the bioluminescence was 6-11-fold higher in strains containing the hlyA-luxAB fusion plasmid (Table 2). This difference was apparent both in the absence and presence of PrfA. Plasmid pSP13 is a pSB292 derivative that contains a cloned promoter from a listerial bacteriophage and which is not environmentally regulated by $\mathrm{pH}$, osmolarity, oxidative stress or temperature (S. F. Park \& R. G. Kroll, unpublished data). When this construct was introduced into the strain selection, little difference in luxAB expression occurred between strains (Table 2). This confirmed that PrfA acts as an activator of expression for the $h l y A$ and $p l c A$ genes at the transcriptional level and that luciferase activity was correctly reporting gene expression.

Effect of heat shock and oxidative stress on virulence gene expression

The expression of a variety of bacterial virulence factors is regulated by heat shock and other enviromental

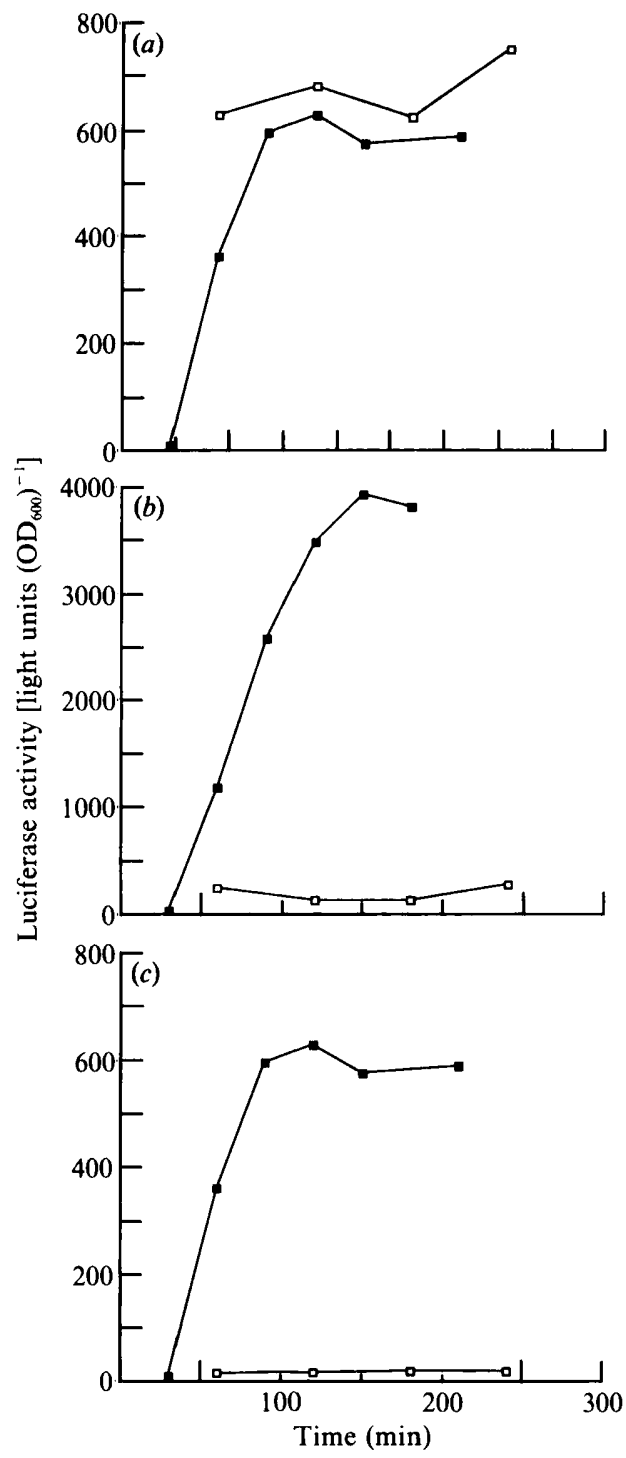

Fig. 3. Heat-shock-induced gene expression in L. monocytogenes from hly $A-l u x A B$ and plcA-luxAB fusions. Strain NCTC 7973, carrying appropriate plasmids, was subjected to heat shock and luciferase activity was assayed at intervals. (a) pSP13, which contained a constitutively expressed luxAB fusion; $(b)$ pSP39, which contained a hly $A-l u x A B$ fusion; (c) pSP38, which contained a plc $A$-lux $A B$ fusion. $\square$, No induction; $\square$, heat shock for $30 \mathrm{~min}$ at $49^{\circ} \mathrm{C}$. Similar results were reproducibly obtained in several experiments.

stresses (Mekalanos, 1992). Recently, Sokolovic \& Goebel (1989) demonstrated that for particular strains of L. monocytogenes, production of listeriolysin $\mathrm{O}$ is induced by heat shock at $48{ }^{\circ} \mathrm{C}$. This has only been analysed qualitatively and no information is available regarding the kinetics of the heat shock induction. The effect of heat shock and oxidative stress on the expression of luciferase from the hly $A$ - and plcA-luxAB fusions were, therefore, studied.

Above $37^{\circ} \mathrm{C}$, bacterial luciferase is irreversibly denatured in L. monocytogenes (S. F. Park \& R. G. Kroll, 
Table 3. Effect of heat shock and oxidative stress on the expression of hlyA-luxAB and plcA-lux $A B$ fusions

The activities correspond to those obtained in a typical experiment. Similar results were reproducibly obtained in several experiments. - , Not tested.

\begin{tabular}{|c|c|c|c|c|c|}
\hline \multirow[b]{2}{*}{ Plasmid/strain } & \multirow[b]{2}{*}{ Relevant characteristics } & \multicolumn{4}{|c|}{ Luciferase activity [light units $\left(O D_{600}\right)^{-1}$ ] } \\
\hline & & TSB & $1 \mathrm{mM}-\mathrm{H}_{2} \mathrm{O}_{2}^{*}$ & $5 \mathrm{mM}-\mathrm{H}_{2} \mathrm{O}_{2}^{*}$ & $49^{\circ} \mathrm{C} \dagger$ \\
\hline pSP13/NCTC 7973 & Constitutive $\operatorname{lu} x A B, p r f A^{+}$ & 750 & 881 & 820 & 590 \\
\hline pSP13/NCTC 10357 & Constitutive luxAB,prfA$\Delta$ & 800 & - & - & 766 \\
\hline pSB38/NCTC 7973 & plcA-luxAB, prfA $A^{+}$ & 20 & 23 & 24 & 410 \\
\hline pSB38/NCTC 10357 & plcA-lux $A B, \operatorname{prf} A \Delta$ & 1 & - & - & 0 \\
\hline pSP39/NCTC 7973 & hly $A-l u x A B, \operatorname{prf} A^{+}$ & 275 & 264 & 262 & 3935 \\
\hline pSP39/NCTC 10357 & hly $A-\operatorname{lux} A B, \operatorname{prf} A \Delta$ & 71 & - & - & 67 \\
\hline
\end{tabular}

* Cells were grown to an $\mathrm{OD}_{600 \mathrm{~nm}}$ of $0 \cdot 2, \mathrm{H}_{2} \mathrm{O}_{2}$ was then added and bioluminescence assessed after $3 \mathrm{~h}$.

† Cells were grown to an $\mathrm{OD}_{600 \mathrm{~nm}}$ of 0.2 and then heat-shocked at $49^{\circ} \mathrm{C}$ for $30 \mathrm{~min}$. Bioluminescence was then assessed after $3 \mathrm{~h}$.

unpublished data). Accordingly, when a strain containing pSP13, in which $\operatorname{lux} A B$ expression appears to be constitutively expressed, was subjected to heat shock, there was an initial abolition of cellular bioluminescence. Resynthesis of luciferase following the heat shock occurred after $30 \mathrm{~min}$, and after $90 \mathrm{~min}$ the levels were restored to pre-heat-shock values (Fig. 3). When expression of luciferase was dependent on the hly $A$ and $p l c A$ promoters, low levels of luciferase activity were again apparent at $30 \mathrm{~min}$. After $60 \mathrm{~min}$, however, the expression of luciferase was stimulated from the plasmids pSB38 and pSB39. The levels of expression from the $h l y A$ and $p l c A$ promoters reached a maximum after $120 \mathrm{~min}$ and were stimulated by 20 -fold and 14 -fold respectively. When the same experiment was carried out in strain NCTC 10357, which does not produce PrfA, no induction of virulence gene expression was observed following heat shock (Table 3). Bacterial cells were subjected to oxidative stress by the inclusion of $\mathrm{H}_{2} \mathrm{O}_{2}$ in the growth media at $1 \mathrm{~mm}$ and $5 \mathrm{~mm}$. An initial decrease in bioluminescence occurred, suggesting that the cells were stressed (data not shown). However, following the restoration of luciferase activity, no induction of gene expression from the hlyA and $p l c A$ promoters occurred (Table 3).

\section{Expression of virulence genes is induced following a} change in cultural conditions

Cultural conditions are known to influence the expression of listeriolysin (Geoffroy et al., 1989). In this study, L. monocytogenes containing the $\operatorname{lu} x A B$ fusion plasmid, pSP39, was routinely cultured in Tryptone Soy Broth when the activity of the hlyA promoter was being assessed. Surprisingly, when TSB-grown cells were transferred to Brain Heart Infusion Broth a dramatic

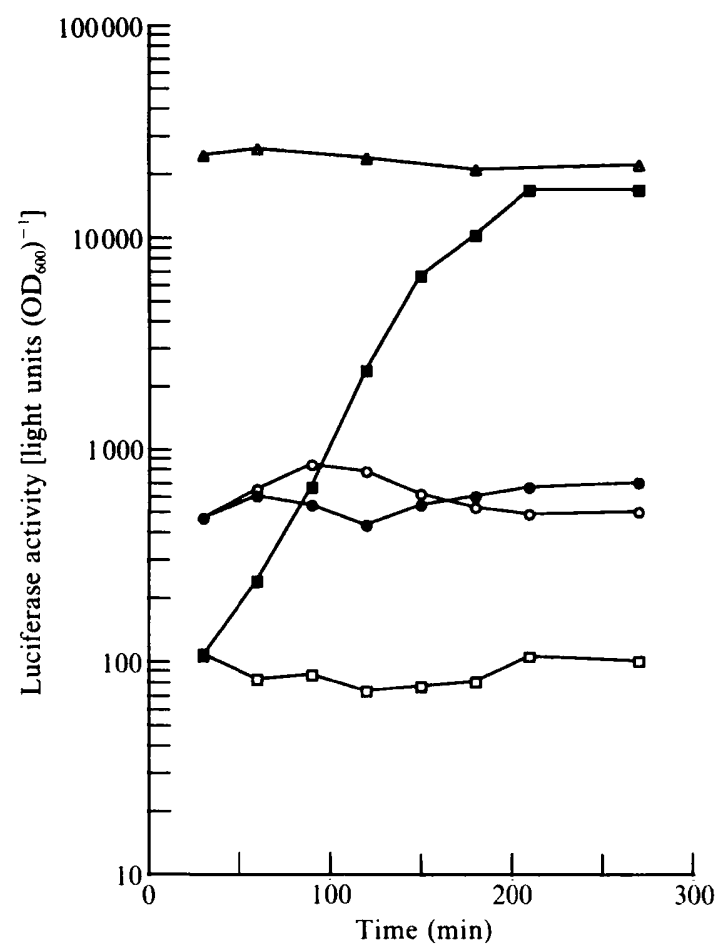

Fig. 4. Induction of $h l y A$ expression by a change in cultural conditions. The luciferase activity from strain NCTC 7973, carrying either the hly $A-$ lux $A B$ fusion plasmid pSB39, or pSP13 in which $\operatorname{luxAB}$ is constitutively expressed, was assayed during growth and transfers into various media. $\square$, pSP39, TSB to TSB; $\mathbf{0}$, pSB39, TSB to BHI; $\triangle$, pSP39, BHI to BHI; O, pSP13, TSB to TSB; $\bullet$, pSP13, TSB to BHI.

induction in the activity of the hly $A$ promoter occurred (Fig. 4). The increase in hly $A$ expression was apparent $60 \mathrm{~min}$ after the transfer into BHI and reached a maximal level after $200 \mathrm{~min}$. At this point, induced levels of hly $A$ expression were 170 -fold greater than those which were measured in TSB. Furthermore, when cells were grown continually in BHI the activity of the hly $A$ 
promoter appeared to be permanently induced (Fig. 4). A similar induction was seen for the plcA promoter following transfer of cells from TSB to BHI (data not shown). No induction of gene expression occurred when the experiment was repeated with the strain of $L$. monocytogenes which carried the plasmid pSP13, in which expression of lux $A B$ is directed by a promoter which appears to be constitutively active (Fig. 4). Moreover, the increase in hly $A$ and $p l c A$ expression was apparent only in cells containing an intact copy of the $\operatorname{prf} A$ gene and, accordingly, when strain NCTC 10357 ( $\operatorname{prf} A \Delta$ ) carrying the plasmids pSP38 or pSP39 was grown in $\mathrm{BHI}$ no induction in the expression of virulence genes was detected (data not shown).

\section{Discussion}

A promoter probe vector for use in $L$. monocytogenes, which utilized the lux $A B$ genes from $V$. fischeri as reporters of gene expression, was constructed. This system allowed the activity of cloned promoters to be assessed readily by measuring cellular bioluminescence. By constructing hly $A$ and $p l c A$ fusions to $u x A B$, we have confirmed that the expression of the virulence factors, listeriolysin $\mathrm{O}$ and phosphatidylinositol-specific phospholipase $\mathrm{C}$, is dependent on the pleiotropic activator of virulence, PrfA, and that regulation occurs at the transcriptional level. When gene fusions are present on multicopy plasmids abnormal regulation of gene expression can occur if regulatory proteins are titrated. The promoter probe system described herein, however, appears to accurately monitor virulence gene expression in $L$. monocytogenes despite the presence of the lux $A B$ gene fusions in trans and on plasmids. The reason for this may be that plasmids with the pCKI replicon are maintained at a relatively low copy number $(<10$ copies per cell; S. F. Park \& R. G. Kroll, unpublished results).

During infection, any pathogen must be able to recognize and respond to multiple environmental cues which signal its entry into the host. Accordingly, environmental stress regulates the expression of a number of bacterial virulence factors (Mekalanos, 1992). Heat shock, for example, is known to induce the synthesis of a characteristic set of proteins in L. monocytogenes, which include the listeriolysin (Sokolovic \& Goebel, 1989; Sokolovic et al., 1990). In this study, the utility of bacterial luciferase as a marker of gene expression has allowed an assessment of the kinetics of heat shock induction of virulence gene expression. The conditions of the heat shock irreversibly denature bacterial luciferase so that any bioluminescence observed after this event must result from re-synthesis of the enzyme. For heat shocked cells of $L$. monocytogenes, in which luciferase was constitutively expressed, a significant time delay was apparent before luciferase activity was restored to pre-shock levels. Presumably, this lag period represents the time it takes the bacterial cell to recover from the heat shock and resume macromolecular synthesis. The same delay in luciferase expression occurred when gene expression was monitored from the promoters of $h l y A$ and $p l c A$. After this initial lag, however, expression of these virulence genes was induced by up to 20 -fold. Heat shock induction of $h l y A$ and plc $A$ did not occur in a (prfA $\Delta)$ mutant strain, but whether or not this effect is regulated by the transcriptional activator, $\operatorname{PrfA}$, is unclear. Recently, Leimeister-Wätcher et al. (1992) demonstrated that expression of virulence genes in L. monocytogenes occurs only when cells are incubated at $37^{\circ} \mathrm{C}$ or above. In our experiments, cells were pre-incubated at $37^{\circ} \mathrm{C}$ prior to heat shock and would already have been induced for virulence gene expression by growth at this temperature (Leimeister-Wätcher et al., 1992). It is possible, therefore, that the induction of hly $A$ and plcA expression described herein represents a true heat shock response rather than it being a manifestation of the thermoregulation of virulence gene expression.

Genetic analysis of the microbial stress response has revealed an interlocked regulatory system (Watson, 1990). For example, in Salmonella typhimurium many proteins induced by heat shock are also induced by oxidative stress (Morgan et al., 1986), and this phenomenon is thought to represent a co-ordinated response to the multiple stresses which are encountered in the macrophage environment (Buchmeier \& Heffron, 1990). In our experiments, however, neither hly $A$ or plcA expression was induced in media containing $\mathrm{H}_{2} \mathrm{O}_{2}$. In contrast, Sokolovic et al. (1990) have reported that an activation of listeriolysin expression occurs during oxidative stress. However, this was only modest compared to the heat shock response and required an extended period of pre-adaption before a complete response occurred.

The composition of growth media for L. monocytogenes is known to affect the expression of listeriolysin but this phenomenon has never been characterized in detail and has been attributed, previously, to iron concentration (Geoffroy et al., 1989). In this study, we have shown for the first time that the expression of at least two virulence genes, $h l y A$ and $p l c A$, is dramatically induced following transfer of L. monocytogenes from TSB to BHI. It is possible that this change in cultural conditions somehow mimics the transition in environmental parameters which enables $L$. monocytogenes to recognize its entry into host tissue and, as a consequence, leads to induction of expression of virulence factors. The nature of the signal(s) that trigger this increase in $h l y A$ and $p l c A$ 
expression is at present unknown, but it is possible to rule out a number of environmental parameters which are known to regulate virulence gene expression in other bacterial pathogens (Mekalanos, 1992). For instance, the TSB and BHI media used in these experiments had equivalent $\mathrm{pH}$ values $(\mathrm{pH} \mathrm{7.4)}$ and the induction of virulence gene expression, therefore, was not dependent on pH. Similarly, both media were unlikely to have had significantly different osmolarities or concentrations of phosphate. Furthermore, both media are considered to be iron replete, so that it is unlikely that iron limitation was responsible for the induction of $h l y A$ and plcA expression that we observed. It is possible, therefore, that the effect of media composition on the expression of virulence factors is due to either the presence of unidentified inducers of virulence in BHI and their absence from TSB or, conversely, the existence of a specific repressor of hlyA and plcA gene expression in TSB. Interestingly, we have also demonstrated that expression of $h l y A$ and $p l c A$ can be induced by heat shock and that this induction in gene expression can occur in TSB. The repression of virulence gene expression during growth in TSB can be overcome, therefore, by additional environmental stimuli which suggests that the regulation of $h l y A$ and $p l c A$ expression can be controlled by multiple environmental signals. A detailed analysis of the mediadependent regulation of hlyA and plcA expression is currently underway in this laboratory; this may lead to the identification of novel factors that mediate the regulation of expression of virulence genes in L. monocytogenes, and which may enable this pathogen to recognize that entry into host tissue has occurred.

\section{References}

Ahmad, K. A. \& Stewart, G. S. A. B. (1988). Cloning of the lux genes into Lactobacillus casei and Streptococcus lactis: phosphate dependent light production. Biochemical Society Transactions 16, 1068.

BARTLETT, J. A., GaILlaRD, R. K. \& JokLIK, W. K. (1986). Sequencing of supercoiled plasmid DNA. Bio/Techniques 4, 208-210.

Buchmeier, N. A. \& Hefrron, F. (1990). Induction of Salmonella stress proteins upon infection of macrophages. Science 248, 730-732.

Camilli, A., Portnoy, D. A. \& Youngman, P. (1990). Insertional mutagenesis of Listeria monocytogenes that allows direct cloning of DNA flanking transposon insertions. Journal of Bacteriology 172 , 3738-3744.

Camilli, A., Goldfine, H. \& Portnoy, D. A. (1991). Listeria monocytogenes mutants lacking phophatidyl-specific phospholipase $\mathrm{C}$ are avirulent. Journal of Experimental Medicine 73, 751-754.

Chakraborty, T., Leimeister-Wächter, M., Domann, E., Hartl, M., Gozbel, W., Nichterlein, T. \& Notermans, S. (1992). Coordinate regulation of virulence genes in Listeria monocytogenes requires the product of the prfA gene. Journal of Bacteriology 174, 568-574.

Cossart, P. \& Mengaud, J. (1989). Listeria monocytogenes, a model system for the molecular study of intracellular parasitism. Molecular Biology and Medicine 6, 463-474.
DomanN, E., LeIMeISTER-WÄChteR, M., GoEbel, W. \& Chakraborty, T. (1991). Molecular cloning of a metalloprotease gene from Listeria monocytogenes that is species specific and physically linked to the listeriolysin gene. Infection and Immunity 59, 65-72.

Farber, J. M. \& Peterkin, P. T. (1991). Listeria monocytogenes, a food borne pathogen. Microbiological Reviews 55, 476-511.

Gaillard, J. L., Berche, P. \& SansonetTi, P. (1986). Transposon mutagenesis as a tool to study the role of haemolysin in the virulence of Listeria monocytogenes. Infection and Immunity 52, 50-55.

Gasson, M. J. \& ANDERSON, P. H. (1985). High copy number vectors for use in lactic streptococci. FEMS Microbiology Letters 30 , 193-198.

Geoffroy, C., Gaillard, J.-L., Alouf, J. E. \& Berche, P. (1989). Production of thiol-dependent haemolysins by Listeria monocytogenes and related species. Journal of General Microbiology 135, 481-487.

Lane, D. J., Pace, B., Olseng. J., Stahl, D. A., Sogin, M. L. \& Pace, N. R. (1985). Rapid determination of 16S ribosomal RNA sequences for phylogenetic analysis in bacteria. Proceedings of the National Academy of Sciences of the United States of America 82, 6955-6969.

Leimeister-WÄChter, M., HAFFNeR, C., DomanN, E., Goebel, W. \& ChaKRABORTY, T. (1990). Identification of a gene that positively regulates expression of listeriolysin, the major virulence factor of Listeria monocytogenes. Proceedings of the National Academy of Sciences of the United States of America 87, 8336-8340.

Leimeister-Wächter, M., DomanN, E. \& Chakraborty, T. (1991). Detection of a gene encoding a phosphatidyl-inositol-specific phopholipase $\mathbf{C}$ that is coordinately expressed with listeriolysin in Listeria monocytogenes. Molecular Microbiology 5, 361-366.

Leimeister-WächteR, M., DomanN, E. \& ChaKRaborty, T. (1992). The expression of virulence genes in Listeria monocytogenes is thermoregulated. Journal of Bacteriology 174, 947-952.

MACKANESS, G. B. (1962). Cellular resistance to infection. Journal of Experimental Medicine 116, 381-406.

Maniatis, T., Fritsch, E. F. \& SAmbrook, J. (1982). Molecular Cloning: a Laboratory Manual. Cold Spring Harbor, NY: Cold Spring Harbor Laboratory.

Meighen, E. A. (1991). Molecular biology of bacterial bioluminescence. Microbiological Reviews 55, 123-142.

MEKALANOS, J. (1992). Environmental signals controlling expression of virulence determinants in bacteria. Journal of Bacteriology 174, 1-7.

Mengaud, J., Vincente, M. F., Chenevert, J., Moniz Pereira, J., Geoffroy, C., Gicquel-Sanzey, B., Baquero, F., Perez-Diaz, J. C. \& Cossart, P. (1988). Expression in E. coli and sequence analysis of the listeriolysin $\mathrm{O}$ determinant of Listeria monocytogenes. Infection and Immunity 56, 766-772.

Mengaud, J., Vincente, M. F. \& Cossart, P. (1989). Transcriptional mapping and nucleotide sequence of the Listeria monocytogenes hly $A$ region reveal structural features that may be involved in regulation. Infection and Immunity 57, 3695-3701.

Mengaud, J., Braun-Breton, C. \& Cossart, P. (1991a). Identification of phophatidylinositol specific phopholipase $\mathrm{C}$ activity in Listeria monocytogenes: a novel type of virulence factor. Molecular Microbiology 5, 367-372.

Mengaud, J., Geoffroy, C. \& Cossart. P. (1991 b). Identification of a novel operon involved in virulence of Listeria monocytogenes: its first gene encodes a protein homologous to bacterial metalloproteases. Infection and Immunity 59, 1043-1049.

Mengaud, J., Dramsi, S., Govin, E., Vazquez-Boland, J. A., Milon, G. \& Cossart, P. (1991 c). Pleiotropic control of Listeria monocytogenes virulence factors by a gene that is autoregulated. Molecular Microbiology 5, 2273-2283.

Michel, E., Beich, K. A., Favur, R., Berche, P. \& Cossart, P. (1990). Attenuated mutants of the intracellular bacterium Listeria monocytogenes obtained by single amino acid substitution in listeriolysin O. Molecular Microbiology 4, 2167-2178.

Morgan, R. W., Christman, M. F., Jacobson, F. S., Stortz, G. \& AMES, B. (1986). Hydrogen peroxide inducible proteins in Salmonella typhimurium overlap with heat-shock and other stress proteins. Proceedings of the National Academy of Sciences of the United States of America 83, 8059-8063. 
PARK, S. F. \& Stewart, G. S. A. B. (1990). High efficiency transformation of Listeria monocytogenes by electroporation of penicillin treated cells. Gene 94, 129-132.

Pitcher, D. G., Saunders, N. A. \& Owen, R. J. (1989). Rapid extraction of bacterial genomic DNA with gaunidium thiocyanate. Letters in Applied Microbiology 8, 151-156.

Rasmussen, O. F., Beck, T., Olsen, J. E., Dons, L. \& Rossen, L. (1991). Listeria monocytogenes isolates can be classified into two major types according to the sequence of the listeriolysin gene. Infection and Immunity 59, 3945-3951.

Silhavy, T. J. \& BeCKWITH, J. (1985). Uses of lac fusions for the study of biological problems. Microbiological Reviews 49, 398-418.
Sokolivic, Z. \& GoEbel, W. (1989). Synthesis of Listeriolysin in Listeria monocytogenes under heat shock conditions. Infection and Immunity 57, 295-298.

Sokolovic, Z., FuCHS, A. \& GoEbel, W. (1990). Synthesis of speciesspecific stress proteins by virulent strains of Listeria monocytogenes. Infection and Immunity 58, 3582-3587.

VazQuez-Boland, J. A., Kocks, C., Dramsi, S., Ohayon, H., Geoffroy, C., Mengaud, J. \& Cossart, P. (1992). Nucleotide sequence of the lecithinase operon of Listeria monocytogenes and possible role of lecithinase in cell-to-cell spread. Infection and Immunity 60, 219-230.

W ATSON, K. (1990). Microbial stress proteins. Advances in Microbial Physiology 31, 183-223. 